DOI: https://doi.org/10.47233/jteksis.v1i1.1

\title{
PERANCANGAN DAN IMPLEMENTASI SISTEM INFORMASI MANAJEMEN ASET PADA PEMERINTAH KABUPATEN MERANGIN MENGGUNAKAN BAHASA PEMROGRAMAN PHP DAN MYSQL
}

\author{
Sularno 1), Nori Sahrun 2) \\ ${ }^{1}$ Sistem Informasi Universitas Dharma Andalas \\ email : soelarno@unidha.ac.id \\ ${ }^{2}$ Sekolah Tinggi Ilmu Ekonomi Riau \\ email : norisahrun84@gmail.com
}

\begin{abstract}
Asset managements is most needed by every businessm especially in recording asset at the local government agencies. Setting is done so that each asset procurement of equipment and goods in these institutions can be properly maintained. In the presence of an inegrated asset management system within the scope of government Merangin to perform data collection and monitoring of assets that can be used as guidelines for decision-making in procurement and rejuvenation of government asset.
\end{abstract}

Keyword :government, assets, businessm

\subsection{Latar Belakang}

Peran sistem informasi terhadap kemajuan organisasi sudah tidak diragukan lagi. Dengan dukungan sistem informasi yang baik maka sebuah lembaga akan memiliki berbagai keunggulan kompetentif sehingga mampu bersaing dengan lembaga lain. Aset atau harta adalah benda baik yang memiliki wujud maupun semu yang dimiliki oleh perusahaan.

Divisi Logistik adalah divisi yang berkewenangan mengelola data asset tetap di Pemerintah Kabupaten Merangin, jenis aset yang dikelola oleh Divisi Logistik yaitu harta tetap atau aktiva tetap atau fixed assets yang berarti harta yang menunjang kegiatan operasional pemerintah yang sifatnya permanen kepemilikannya. Macam-macam aset yang di kelola Divisi Logistik yaitu tanah, gedung, mesin-mesin, perkakas dan alat bantu, perlengkapan dan untility, alat angkut angkat, alat kantor, dan aktiva tetap lainnya.
Pengolahan Sistem Informasi Manajemen Aset merupakan bagian penting untuk mengetahui perkembangan kinerja

dan mutu sebuah lembaga. sistem pengolahan data aset yang sedang berjalan saat ini di kabupaten Merangin masih mengacu pada sistem manual dengan menggunakan berkas-berkas sebagai sarana pendokumentasian data. Pengolahan data dengan cara ini dinilai banyak menimbulkan masalah pada pemrosesan data aset, seperti pada saat proses pengecekan barang yaitu pengendalian terhadap pemakaian barang disetiap divisi kurang terkontrol karena pemakaian barang tidak terinci sehingga tidak diketahui dengan pasti berapa jumlah barang atau peralatan kantor yang masih tersedia dan kondisi barang yang masih bisa dipergunakan.

\subsection{Perumusan Masalah}

Berdasarkan pengamatan penulis dalam pembuatan tugas akhir ini dapat disimpulkan permasalahan utama adalah sebagai berikut : 
1. Bagaimana proses pengolahan data manajemen aset dilakukan secara komputerisasi?

2. Apakah sistem informasi manajemen aset yang dirancang dengan menggunakan bahasa pemograman PHPMySQL dapat membantu dalam pendataan dan manajemen aset sehingga dapat meningkatkan efisiensi dan efektifitas kerja?.

3. Bagaimana meningkatkan keamanan data manajemen aset yang belum terjamin keamanan datanya.

4. Bagaimana implementasi sistem informasi manajemen aset pada Pemerintah Kabupaten Merangin?.

\subsection{Hipotesis}

Hipotesis merupakan dugaan sementara yang akan diteliti dan dibuat. Berdasarkan perumusan masalah di atas, maka dibuat hipotesis yang akan mengatasi masalah dalam melakukan manajemen aset yang diharapkan :

1. Agar suatu sistem dapat berjalan sesuai dengan harapan, maka terlebih dahulu harus memahami sistem yang sedang berjalan dan konsep pemrograman PHP dan MySQL

2. Memberikan kemudahan kepada masing-masing devisi dalam mengrimkan data laporan aset ke Kantor kantor pusat.

3. Data-data yang berhubungan dengan informasi penjualan dapat lebih aman dengan ditempatkan pada media penyimpanan yang lebih baik dan tepat.

1. Dengan adanya sistem manajemen aset yang disediakan oleh Pemerintah Kabupaten Merangin setiap devisi diharapkan berjalan maksimal dan menghasilkan data yang akurat.

\subsection{LANDASAN TEORI}

2.1 Konsep Dasar Sistem Informasi

2.1.1 Sistem informasi bukan merupakan hal yang baru. Yang baru adalah komputerisasinya. Sebelum ada komputer, teknik penyaluran informasi yang memungkinkan manajer merencanakan serta mengendalikan sudah ada.

\subsubsection{Pengertian Sistem}

Sistem pada dasarnya adalah sekelompok unsur yang sangat erat hubungannya satu dengan yang lain, yang berfungsi bersama-sama untuk mencapai suatu tujuan (Tata Sutabri,2012:6).

2.1.2

\subsection{Alat Bantu Perancangan Model Sistem} Informasi

\subsubsection{Unified Modelling Language (UML)}

Pada perkembangan teknologi perangkat lunak, diperlukan adanya bahasa yang digunakan untuk memodelkan perangkat lunak yang akan dibuat dan perlu adanya standarisasi agar orang dapat mengerti pemodelan perangkat lunak.

\section{Unified Modeling Language} merupakan bahasa visual untuk pemodelan dan komunikasi mengenai sebuah sistem dengan menggunakan diagram dan teks-teks pendukung (Rosa A.S.-M.

\section{Shalahuddin,2011:118).}

Dalam arti lainnya, UML juga dapat didefinisikan sebagai sebuah standarisasi bahasa pemodelan untuk membangun perangkat lunak yang dibangun menggunakan teknik pemrograman berorientasi objek.

\subsubsection{Diagram Unified Modelling Language (UML)}

Diagram berbentuk grafik yang menunjukkan simbol elemen model yang disusun untuk mengilustrasikan bagian atau aspek tertentu dari sistem. Sebuah diagram merupakan bagian dari suatu view tertentu dan ketika 
digambarkan biasanya dialokasikan untuk view tertentu. Adapun jenis diagram antara lain :

\subsection{Konsep Dasar Database \\ 2.3.1 Database}

Sistem basis data adalah sistem terkomputerisasi yang tujuan utamanya adalah memelihara data yang sudah diolah atau informasi dan membuat informasi tersedia saat dibutuhkan. Pada intinya basia data adalah mediantuk menyimpan data agar dapat diakses dengan mudah dan cepat (Rosa A.S.-M.Shalahuddin,2011).

\subsection{Konsep Dasar MySQL dan Pemrograman PHP}

\subsubsection{Sekilas Mengenai MySQL}

MySQL adalah Relational Database Management Sistem (RDBMS) yang didistribusikan secara gratis di bawah licensi GPL (GeneralPublic License). Dimana setiap orang bebas untuk menggunakan MySQL, namun tidak boleh dijadikan produk turunan yang bersifat close source atau komersial.MySQL sebenarnya merupakan turunan salah satu konsep utama dalam database sejak lama yaitu, SQL (Structured Query Language). SQLadalah sebuah konsep pengoperasian database, terutam untuk pemilihan/seleksi dan pemasukan data, yang memungkinkan pengoperasian data dikerjakan dengan mudah secara otomatis. Keandalan suatu sistem database (DBMS) dapat diketahui dari cara kerja optimizer-nya dalam melakukan proses perintah perintah SQL, yang dibuat oleh user maupun program-program aplikasinya. Sebagai database server, MySQL dapat dikatakan lebih unggul dibandingkan database server lainnya dalam query data. Hal ini terbukti untuk query yang dilakukan oleh single user, kecepatan query MySQL bisa sepuluh kali lebih cepat dari PostgreSQL dan lima kali lebih cepat dibandingkan Interbase. Kemampuan yang cukup menakjubkan untuk sebuah software gratisan.
PHP adalah salah satu bahasa pemrograman yang berjalan dalam sebuah webserver dan berfungsi sebagai pengolah data pada sebuah server (Madcoms,2012:206).

\section{ANALISA DAN HASIL}

\subsection{Analisa Sistem}

Analisa sistem dapat didefinisikan sebagai penguraian dari suatu sistem informasi yang utuh ke dalam bagian-bagian komponennya dengan maksud untuk mengidentifikasi dan mengevaluasi permasalahan-permasalahan, kesempatan-kesempatan, hambatanhambatan yang terjadi dan kebutuhankebutuhan yang diharapkan sehingga dapat diusulkan perbaikan-perbaikannya.

\subsection{Disain Sistem Baru}

\subsubsection{Perancangan Aplikasi Menggunakan Use Case Diagram}

Use case diagram menggambarkan fungsionalitas yang diharapkan dari sebuah sistem. Use case merepresentasikan sebuah interaksi antara aktor dengan sistem. Seorang/sebuah aktor adalah sebuah entitas manusia atau mesin yang berinteraksi dengan sistem untuk melakukan pekerjaan-pekerjaan tertentu. Use case merupakan sebuah pekerjaan tertentu, misalnya login ke sistem, meng-create sebuah daftar belanja, dan sebagainya.

\subsubsection{Sekilas Tentang PHP}




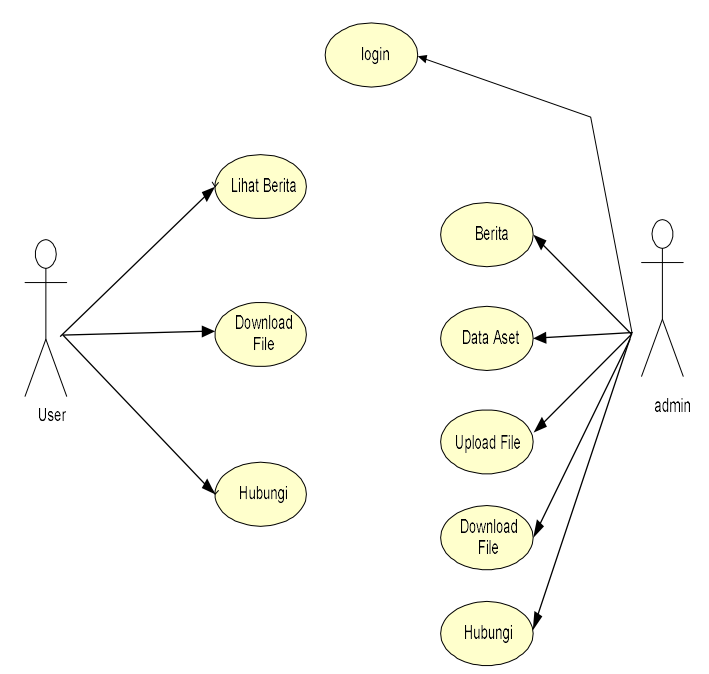

Gambar 3.1 Use Case Diagram

3.2.2 Perancangan Aplikasi Menggunakan Class Diagram

Class diagram menggambarkan bagaimana struktur dari perancangan sistem. Semua proses yang dilakukan oleh aktor terhadap aplikasi akan didefinisikan dengan menggunakan class diagram. Class diagram menunjukkan bentuk visualisasi dalam pembuatan sistem. Masingmasing class memiliki attribute dan metoda/fungsi sesuai dengan proses yang terjadi. Adapun bentuk class diagram dari aplikasi manajemen aset dapat dilihat pada Gambar 3.3.

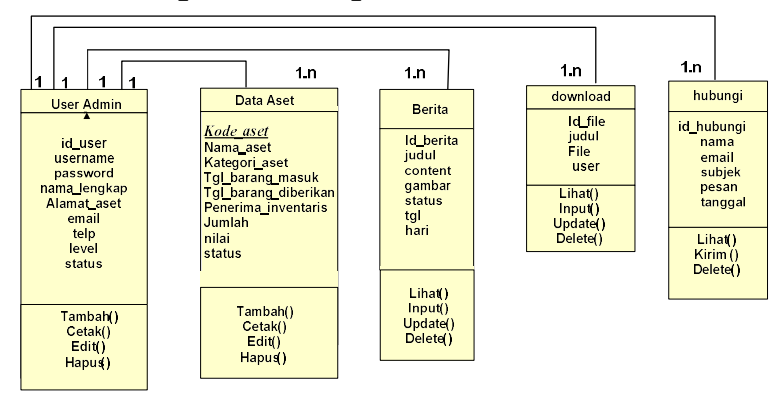

\section{Gambar 3.2 Class Diagram \\ 4. IMPELEMENTASI DAN \\ PENGUJIAN SISTEM}

4.1 Implementasi Sistem

1. Order hosting dan domain

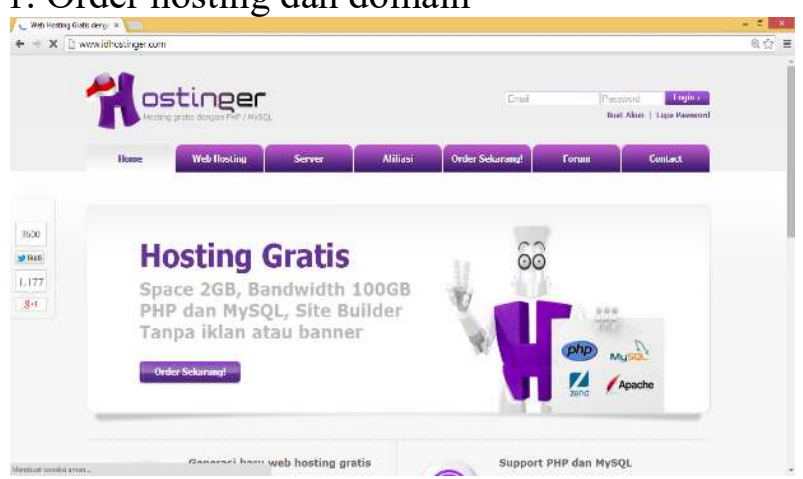

Gambar 4.1 Situs Penyedia Layanan Domain dan Hosting

2. Membuat Nama Domain dan Hosting

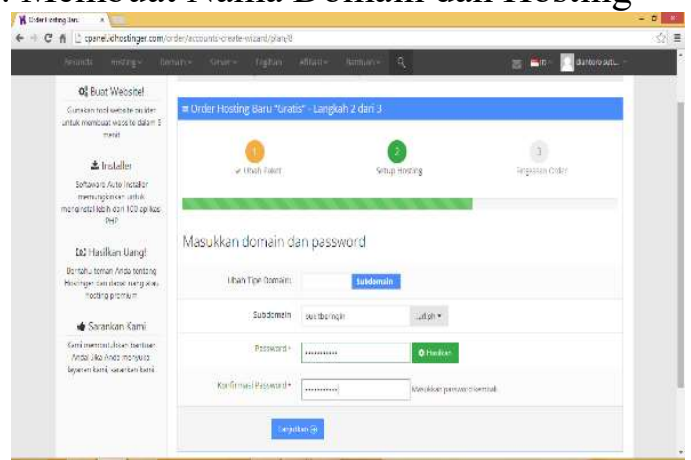

Gambar 4.2 Halaman pembuatan Nama Domain

3. Upload File Melalui Filezilla

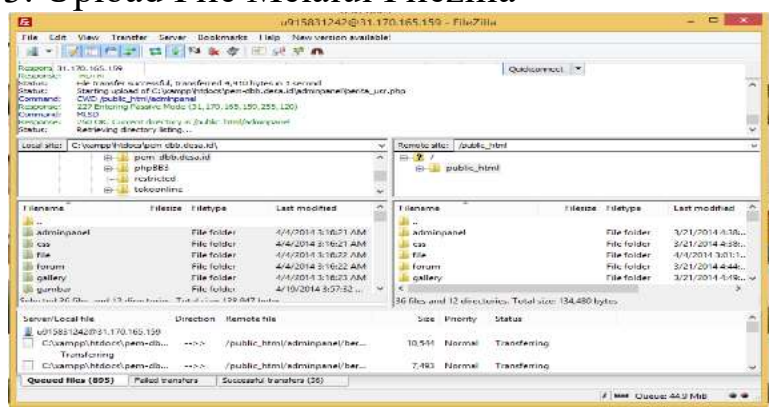

Gambar 4.3 Upload File Menggunakan Filezilla 


\subsection{Pengujian Sistem}

1. Halaman Depan Website (Homepage)

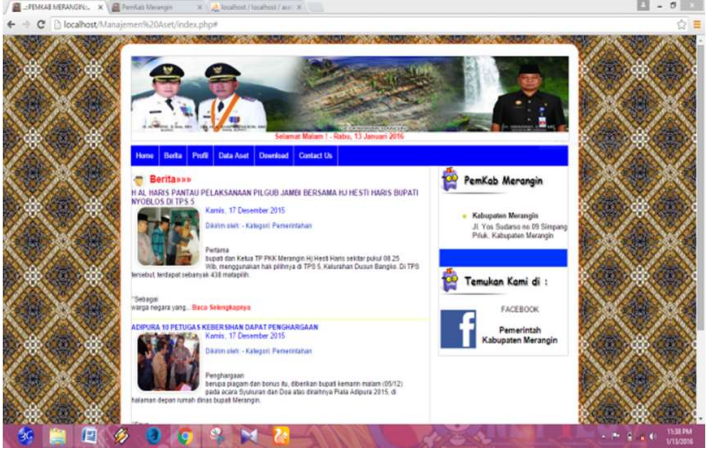

Gambar 4.7 Tampilan Halaman Utama Website

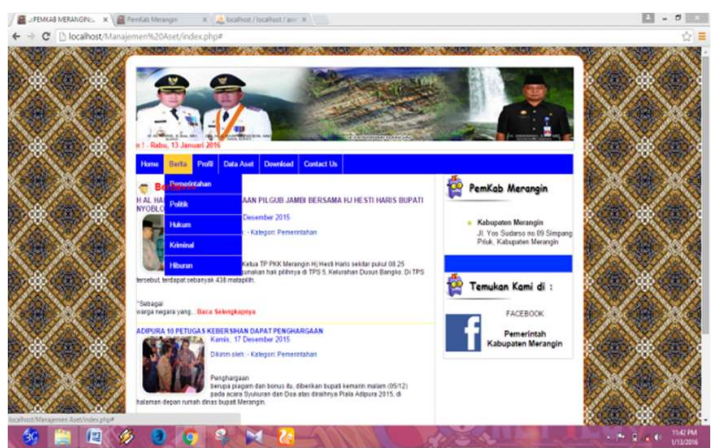

\section{Gambar 4.8 Tampilan Halaman Pilihan} Berita

3. Halaman Melihat Pilihan Berita

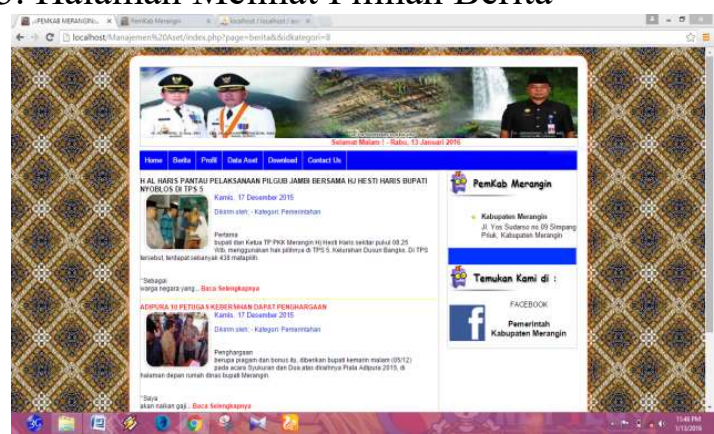

Gambar 4.9 Tampilan Halaman Pilihan Profil

4.Halaman Melihat Pilihan Berita

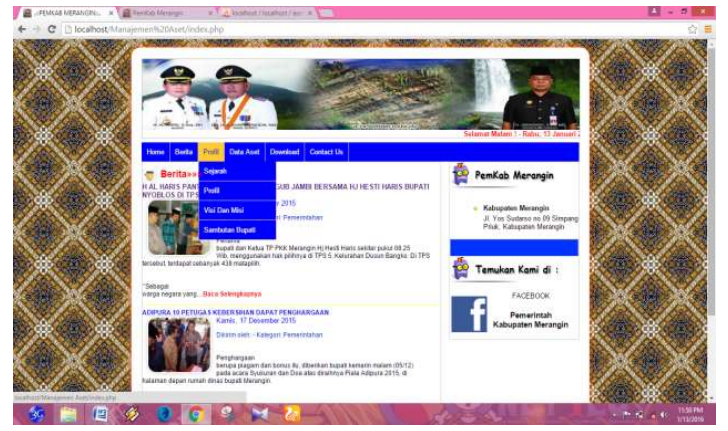

Gambar 4.10 Tampilan Halaman Melihat Pilihan Berita

5. Halaman Sejarah

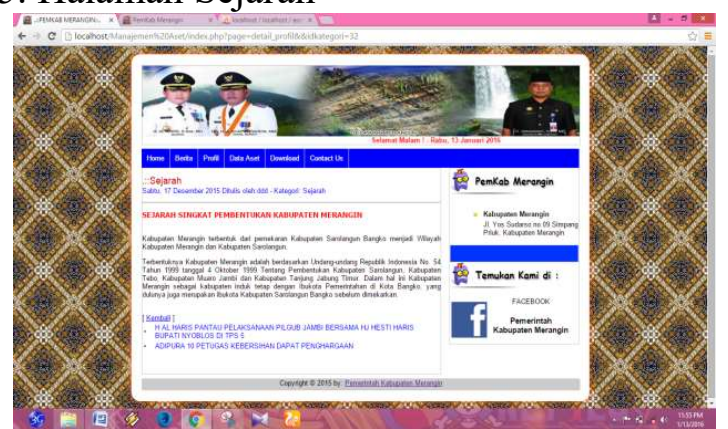

Gambar 4.11 Tampilan Halaman Melihat Sejarah

6. Halaman Melihat Data Aset

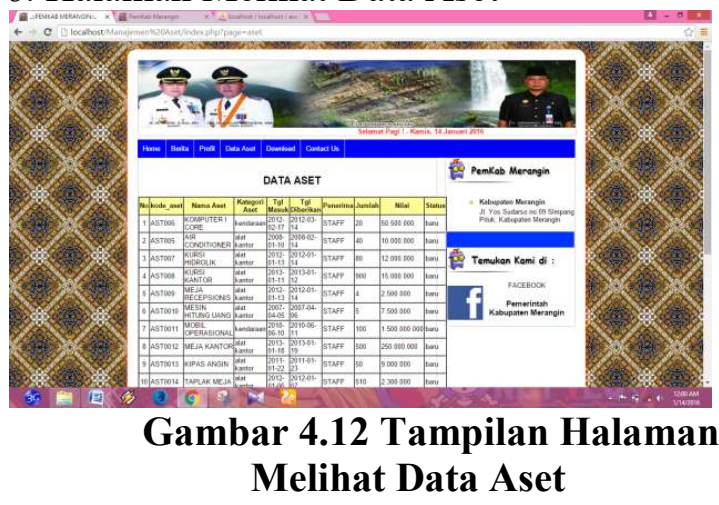

\section{PENUTUP}

Kesimpulan

Sehubungan dengan analisa yang dilakukan pada Pemerintahan Kabupaten Merangin tentang permasalahan Manajemen Aset dengan metode penelitian yang telah diuraikan pada bab-bab sebelumnya, maka dapat diambil kesimpulan sebagai berikut: 
1. Dengan perancangan Website dapat mengelola manajemen aset Pemerintah Kabupaten Merangin.

2. Dengan menggunakan Website dapat memudahkan dalam memonitoring data aset pada Pemerintah Kabupaten Merangin.

3. Dengan menggunakan Website sebagai sistem pengelolaan aset Pemerintahan Kabupaten Merangin dapat mempermudah pada petugas bidang pendataan aset.

4. Dengan rancangan sistem yang baru, pembuatan laporan-laporan yang berhubungan dengan informasi aset dapat dibuat secara cepat, tepat dan dapat meminimalkan kesalahan-kesalahan.

\section{Saran}

Setelah penulis menyelesaikan tahap akhir dari penelitian ini, penulis menyadari masih banyak kekurangan-kekurangan yang mesti diperbaiki dan dipenuhi, antara lain :

1. Dalam peningkatan kualitas pelayanan pendataan manajemen aset, hasil penelitian ini dijadikan sebagai bahan pertimbangan bagi pihak pemerintah Kabupaten Merangin.

2. Agar sistem yang dirancang dapat bekerja secara efektif dan efisien maka diperlukan tenaga terampil dalam pengoperasian aplikasi yang dibuat.

3. Dalam menerapkan sistem komputerisasi sebaiknya didukung oleh perangkat yang memadai, baik dari segi manusia (Brainware) maupun segi peralatannya (Software dan Hardware).

\section{DAFTAR PUSTAKA}

\section{A.S. Rosa dan M. Salahuddin.}

2011.ModulPembelajaranRekayasaP erangkatLunak(

TerstrukturdanBerorientasiObjek

).Bandung : Modula

Kadir, Abdul. 2010. MudahMempelajari Database MySQL. Yogyakarta: CV Andi Offset
Madcoms. 2011.MembongkarMisteri Adobe Dreamweaver CS6 dengan PHP \& MySQL. Yogyakarta: CV Andi Offset.

Madcoms. 2008.TeknikMudahMembangun Website dengan HTML,PHP, Dan MySQL. Yogyakarta: CV Andi Offset.

Madcoms. 2012. Adobe Dreamweaver CS6 \& PHP - MySQL UntukPemula. Yogyakarta: CV Andi Offset.

Sibero, F.K. Alexander. 2011. KitabSuci Web Programming. Yogyakarta: MediaKom

Sutabri, Tata. 2012. AnalisSistemInformasi. Yogyakarta: CV Andi Offset.

Tantra,

Rudy.2012.ManajemenProyekSistem Informasi.Yogyakarta $\mathrm{CV}$ AndiOffset 